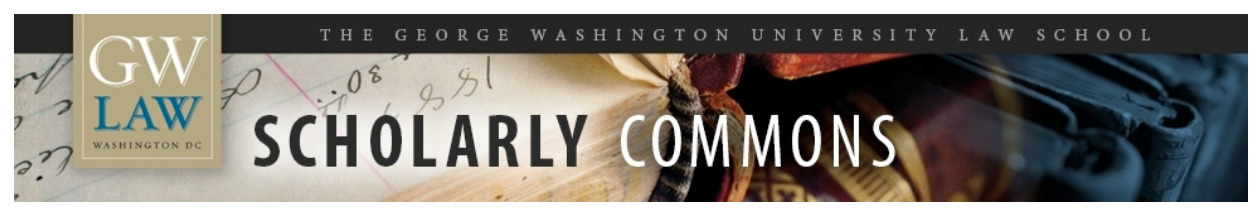

\title{
Organizational Conflicts of Interest: A Growing Integrity Challenge
}

Daniel I. Gordon

George Washington University Law School, dgordon@law.gwu.edu

Follow this and additional works at: https://scholarship.law.gwu.edu/faculty_publications

Part of the Government Contracts Commons

\section{Recommended Citation}

Gordon, Daniel I., "Organizational Conflicts of Interest: A Growing Integrity Challenge" (2005). GW Law Faculty Publications \& Other Works. 603.

https://scholarship.law.gwu.edu/faculty_publications/603

This Article is brought to you for free and open access by the Faculty Scholarship at Scholarly Commons. It has been accepted for inclusion in GW Law Faculty Publications \& Other Works by an authorized administrator of Scholarly Commons. For more information, please contact spagel@law.gwu.edu. 


\title{
Organizational Conflicts of Interest: A Growing Integrity Challenge
}

\author{
Daniel I. Gordon ${ }^{1}$
}

Conflicts of interest involving government officials have been very much in the news in recent years. ${ }^{2}$ At least in the United States, public procurement professionals are encountering more and more instances of a more particular kind of conflict, organizational conflicts of interest (OCIs), which can be defined, initially, as situations where an entity plays two or more roles that are, in some sense, at odds with one another. This article endeavors to set out some points for consideration in this increasingly important area. That we are seeing an increase in the frequency of OCIs can hardly be doubted. ${ }^{3}$ As discussed below, alleged OCIs have been identified in various activities of

\footnotetext{
${ }^{1}$ Mr. Gordon is Managing Associate General Counsel at the U.S. Government Accountability Office (GAO), where he heads the unit handling bid protests. The views in this article are Mr. Gordon's, and should not be read as those of GAO. The author thanks Jonathan L. Kang, a senior attorney in GAO's bid protest office, for his significant assistance in researching and editing the article. This article is a working draft that is presented for purposes of discussion at the "Organizational Conflicts of Interest: New Challenges” conference at The George Washington University Law School on February 8, 2005. ${ }^{2}$ On just one recent day, September 24, 2004, The Washington Post had two articles discussing alleged conflicts of interest involving U.S. Government officials--one involving the Secretary of the Air Force and another involving scientists at the National Institutes of Health. See Renae Merle, Boeing Deal Faces Justice Dept. Review; Potential Conflict of Interest Cited, WASH. Post, Sept. 24, 2004, at A4; Rick Weiss, NIH Bans Collaboration With Outside Companies; Policy Comes After Conflict-of-Interest Inquiry, WASH. Post, Sept. 24, 2004, at A23. The "revolving door" phenomenon (referring to individuals moving between the public and private sectors) has led to complaints about conflicts of interest. The most noteworthy recent case in the federal context may be the situation where a senior Air Force procurement official, Darleen Druyun, is said to have had employment discussions with Boeing while she was still at the Air Force and while she was involved in negotiations with Boeing about the award of a large contract to that company. Watchdog Group Targets Contractors' Hiring, Campaign Contributions, 18 No. 7 ANDREWS Gov’T ConT. LiTIG. ReP. 13 (Aug. 2, 2004) (citing a report by the Project on Government Oversight watchdog group calling Druyun "a poster child for the ills of the revolving door"). For an example of the attention given to conflicts of interest involving government officials in the European context, see Tobias Buck, EU's New Competition Chief in Conflicts Fears, FIN. TIMES, Sept. 16, 2004, at 1 (citing an alleged conflict of interest involving the person slated to be the European Union's competition commissioner). Conflicts of interest arise in many different contexts, far beyond the narrow scope of this article. For an example of conflicts of interest outside the world of government, see Alec Klein, When Interests Collide: Credit Raters Subject to Client Pressure, WASH. Post, Nov. 22, 2004, at A9 (rating companies may be in situation where their interest in obtaining fees for conducting ratings conflicts with the need for objectivity).

${ }^{3}$ For historical background on the rise of OCIs and early efforts to address them, see Daniel Guttman, Organizational Conflict of Interest and the Growth of Big Government, 15 HARV. J. ON LEGIS. 297 (1977-78) (emphasizing that initial restrictions on OCIs were designed to protect competitors, not the public interest); Organizational Conflicts of Interest in Government Contracting, 1991 A.B.A. SEC. PUB. ConT., at 4-11. See also, Charles D. Woodruff, Organizational Conflicts of Interest--Not What It's Been Said To Be, 16 PuB. ConT. L.J. 213 (Aug. 1986); James W. Taylor and B. Alan Dickson, Organizational Conflicts of Interest Under the Federal Acquisition Regulation, 15 PuB. ConT. L.J. 107, 107-110 (Aug. 1984); James W. Taylor, Organizational Conflicts of Interest in Department of Defense Contracting, 14 PuB. ConT. L.J. 158, 162-165 (Oct. 1983). For analysis of OCIs in both a historical context and the context of the current debate over "competitive sourcing," see Dan Guttman, Governance by Contract: Constitutional Visions: Time for Reflection and Choice, 33 PuB. ConT. L.J. 321 (Winter 2004).
} 
the U.S. federal procurement process, from contracts for security services in Iraq to public/private competitions for work to be performed in the U.S. This article first suggests reasons for the increasing frequency of OCIs, then steps back to analyze the elements of conflicts of interest and of OCIs, and then addresses the legal framework and caselaw related to OCIs in the U.S. federal procurement system. ${ }^{4}$

\section{Possible Reasons for the Increasing Frequency of OCIs}

A number of reasons can be offered as possible explanations for the apparently increasing number of OCIs in federal procurements. First, the consolidation within the industries serving the U.S. Government, particularly in the information technology and defense industries, has caused OCIs to be a more common problem. ${ }^{5}$ This goes beyond having fewer contractors who produce a particular good or service; the contractors that remain are producing a wider range of goods and services than they did previously, and it is this change that is increasing the risk of OCIs. ${ }^{6}$

Second, the Government is obtaining more and more services from contractors, and those services are increasingly likely to entail the exercise of judgment: rather than merely obtaining computer-repair services from private firms, for example, the Government is entering into contracts that include the firms giving the Government advice on which hardware or software to buy. ${ }^{7}$ With fewer firms playing an increasing number of roles, and those roles increasingly involving the exercise of judgment, there is a greater chance that a firm will "trip over itself," so to speak. If Firm ABC is a vendor of computer software and Firm DEF is a vendor of advice on which computer software to buy, they may both be able to sell to the government without risk of a conflict of interest; if, however, Firm ABC buys Firm DEF, the DEF segment of the combined entity will have a conflict of interest when it recommends that the government buy ABC's software rather than that of a competitor.

Third, the use of contract vehicles that invite "marketing" by the contractor risks fostering OCIs. More and more frequently, the federal government is awarding “umbrella” contracts (technically, indefinite-delivery/indefinite-quantity contracts), often to multiple companies and covering multiple federal agencies. ${ }^{8}$ Those contracts typically provide only a very low guaranteed minimum dollar value, so that the amount of revenue

\footnotetext{
${ }^{4}$ This article discusses OCIs primarily as litigated in bid protests within the federal procurement system. However, this focus should not be taken as an exhaustive review of every possible scenario in which OCIs may arise within other areas of the federal procurement system.

${ }^{5}$ See Thomas J. Madden, John J. Pavlick, Jr., and James F. Worrall, Organizational Conflicts of Interest/Edition III, 94-08 BRIEFING PAPERS 1 (July 1994).

${ }^{6}$ See Jonathan Karp and Andy Pasztor, Can Defense Contractors Police Their Rivals Without Conflicts?, WALL ST. J., Dec. 28, 2004, at A1 (referring to defense industry mergers narrowing the Pentagon's options and expanding the product lines of the major suppliers).

${ }^{7}$ See id. (referring to the military's increasing reliance on large contractors to act as its agent in developing and supervising weapons programs, and the challenges that large contractors' dual roles create).

${ }^{8}$ See Federal Acquisition Regulation (FAR) subpart 16.5 (indefinite-delivery contracts), subpart 8.4 (federal supply schedules). The "umbrella" contracts are also referred to as "master" contracts, and correspond, at least in some respects, to the "framework agreements" used in the European Union. See EU Directive 2004/18/EC, 2004 O.J. (L 134) 114, Art. 54 (Apr. 30, 2004).
} 
coming in to the contractor may depend on the success of its marketing to federal agencies. In that situation, the contractor has a strong incentive to persuade government buying officials that the goods or services they need are within the scope of the umbrella contract (which makes purchasing them without further competition quite easy). One example of this arose in connection with an umbrella contract held by CACI, Inc., and facilitated by the Department of Interior (under the General Services Administration's Federal Supply Schedule program) for information technology professional services. The recent Army investigation of the treatment of prisoners by the U.S. military at the Abu Ghraib detention facility in Iraq (the Fay Report) found that a CACI employee participated in writing the statement of work for the delivery order covering interrogation services. ${ }^{9}$ When a company expresses a view on whether its umbrella contract includes within its scope the goods or services that a buyer wants, that company may be viewed as having a conflict of interest.

The growing use of umbrella contracts has arguably given rise to another, somewhat novel, kind of OCI. Agency employees who are making the decision about whether particular goods or services are within the scope of a particular umbrella contract may face something of an OCI of their own. In at least some agencies, the agency receives a percentage of the revenue spent under the contracts they administer, and the desire to enhance the agency's revenue stream can create what looks like an OCI, which could affect the agency's objectivity in making determinations about the scope of the contract. Again, the contract under which delivery orders for interrogators at Abu Ghraib was issued could be raised as an example--the Fay Report points out that the umbrella contract was awarded by a "fee for service" activity of the Department of Interior. Agencies' receipt of these commissions or fees (sometimes called "industrial funding fees”) can, at least arguably, be said to create OCIs for government agencies.

\section{Elements of a Conflict of Interest}

OCIs are a subset of conflicts of interest, and, in analyzing them, it is therefore worthwhile to see them in the context of conflicts of interest generally. Some definitions of conflicts of interest refer to them as a situation where a person is torn between duties (or loyalty) to two or more different parties. ${ }^{10}$ Thus, where an attorney represents multiple defendants in a criminal case, the attorney may face a conflict of interest. ${ }^{11}$ The term "conflict of interest" is well suited to these cases, since they arise when someone

\footnotetext{
${ }^{9}$ Major General George R. Fay, Investigation of the Abu Ghraib Detention Facility and 205 ${ }^{\text {th }}$ Military Intelligence Brigade, at 49, available at http://www4.army.mil/ocpa/reports/ar15-6/AR15-6.pdf. For an example of this matter in the press, see CACI reports strong growth, FED. COMPUTER WK, Aug. 30, 2004, at 63. For an example of some key related legal and procurement issues, see Steven L. Schooner, Iraq Contracting: Predictable Lessons Learned, Statement before the U.S. Senate Democratic Policy Committee (Sept. 10, 2004), available at http://www.law.gwu.edu/facweb/sschooner/Sen-Iraq04.pdf.

${ }^{10}$ For example, the online Real Life Dictionary of the Law by Gerald and Kathleen Hill, defines a conflict of interest as "a situation in which a person has a duty to more than one person or organization, but cannot do justice to the actual or potentially adverse interests of both parties." See Law.com Dictionary, available at http://dictionary.law.com.

${ }^{11}$ See Holloway v. Arkansas, 435 U.S. 475 (1978) (discussing conflicts of interest in representing multiple criminal defendants, including cases cited on the subject).
} 
finds him- or herself trying to serve (or to be loyal to) two or more people (or organizations) whose interests conflict with one another. The conflicted person is trying to serve two masters who are pulling in different directions.

At least in federal procurement cases, however, conflicts of interest rarely involve a person trying to serve two masters. An illustration, which, while not a procurement case, may in fact be more typical of conflicts of interest as they arise in procurement cases than the "two masters" model: we might well say that Judge Mary Smith has a conflict of interest in the case of ABC vs. DEF if Judge Smith owns stock in ABC and she is asked to be the presiding judge in the lawsuit--but not because Judge Smith is serving two masters, or serving two conflicting interests outside of herself. The three elements of this conflict of interest are: (1) the conflicted party ${ }^{12}$--here, Judge Smith; (2) an interest that the conflicted party has in the situation--here, Judge Smith's presumed interest in the value of her stock being preserved; and (3) a responsibility that the conflicted party has to a third party--here, Judge Smith's duty to the judicial system to judge the ABC vs. DEF case impartially. Each of the three elements merits further discussion, with the emphasis on how they present themselves in the context of OCIs.

The conflicted party. In a personal conflict of interest, the conflicted party will be a person. In an OCI, the conflicted party will, not surprisingly, be an organization. That difference has at least one key assumption built into it, and some significant implications. The assumption is that all the people and bodies associated with an organization--whether they are agents, officers, employees, officials, or representatives--will treat the organization's interests as, in some sense, their own and want to further them. ${ }^{13}$ That is why we would see a potential conflict of interest in a situation where, if individuals in a firm's research and development office help a government agency draft the specifications for a new weapon system, management in a different office of the same firm wants to compete to build the system for the government. Not only are all employees, agents, etc. of the firm assumed to want to further the firm's interests; this assumption may be extended to all employees, agents, etc. of all affiliates of the firm (subsidiaries, parents, and sister organizations). ${ }^{14}$

The conflicted party's interest in the situation. This is always something that can be readily identified as an "interest," and it is usually a financial interest. That is, the party typically has either money at stake or something else at stake that relates to money (for example, property whose value is at risk, such as Judge Smith's stock, or a job or a promotion). And it is the conflicted party's personal interest (for example, Judge Smith's interest in the value of her stock), not someone else's. We tend to be "stingy" in

\footnotetext{
${ }^{12}$ In much of the discussion that follows, there is a question about whether the party is actually facing a conflict of interest, so that, strictly speaking, it would be more correct to write "allegedly conflicted party." If the word "allegedly" is omitted, it is only for brevity's sake.

${ }^{13}$ One could say that the organization's employees, agents, etc., have an OCI because they are serving two masters: the organization and some other entity. OCIs are not, however, generally viewed this way; instead, it is said that the organization (not the employee) has an OCI. Indeed, that is presumably why we call them organizational conflicts of interest.

${ }^{14}$ See, e.g., ICF, Inc., B-241372, Feb. 6, 1991, 91-1 CPD \ 124 at 1 (finding an OCI created by relationship between firm and its parent and sister corporations).
} 
accepting that any other individual's interest will trigger a personal conflict of interest. For example, we probably would not say that Judge Smith had a conflict of interest just because her neighbor, or her cousin, or one of her friends held stock in ABC, Inc. We might, though, feel she had a conflict of interest if her spouse or life partner held ABC stock (which may explain why the U.S. Senate financial disclosure form requires the person filling it out to identify a spouse's assets). ${ }^{15}$ This narrow focus is in contrast to the tendency to ascribe a desire to further an organization's interest to all its employees, etc., and all of its affiliates and their employees, etc. As the cases discussed later in the article illustrate, in OCIs, the interest is usually as readily identifiable, and as typically financial as is the case with personal conflicts of interest.

The conflicted party's responsibility to a third party. This is the competing "interest" in the conflict. While the conflicted party (or his or her organization) typically has a readily-identifiable interest at stake (and usually a financial one), this other side of the conflict is often one that we might not see as the conflicted party's interest at all. ${ }^{16}$ At most, it could be said that some third party has an "interest" at stake, but that interest is often non-financial and indeed in many cases (perhaps most), the third party is simply trying to obtain an unbiased opinion about something from the conflicted party. To return to our example, the "interest" that conflicts with Judge Smith's interest in the value of her ABC stock is the parties' interest in the fair adjudication of their dispute (presumably DEF is more worried about Judge Smith's stock ownership than ABC is). That is, we say that she has a conflict of interest because her personal stake in ABC stock risks interfering with her ability to fulfill her duty to the judicial system (and the parties) to judge the case fairly and objectively. In other words, the conflicted party's personal-or, in the case of an OCI, the organizational--interest is at odds with the conflicted party's responsibility to a third party, and that responsibility typically entails the providing of fair judgment untainted by personal interest. ${ }^{17}$

\section{Legal Framework Governing OCIs in the Context of U.S. Federal Procurements}

With this analytical framework in mind, let us turn to the legal definitions and categories in the U.S. federal procurement context. The Federal Acquisition Regulation (FAR) defines an OCI as follows: "because of other activities or relationships with other persons, a person is unable or potentially unable to render impartial assistance or advice to the Government, or the person's objectivity in performing the contract work is or might be otherwise impaired, or a person has an unfair competitive advantage."18 In terms of the elements of a conflict of interest set out above, the conflicted party is the

\footnotetext{
${ }^{15}$ See Senate Select Committee on Ethics website, available at http://ethics.senate.gov.

${ }^{16}$ In defining personal conflicts of interest, one author has written of the clash between a public official's interest in performing his (or her) official duties and the official's interest in his (or her) private affairs, "especially his economic affairs.” Robert S. Pasley, Individual Conflicts of Interest, 64-4 BRIEFING PAPERS 7 (Aug. 1964).

${ }^{17}$ See Robert S. Pasley, Organizational Conflicts of Interest, 64-6 BRIEFING PAPERS 97 (Dec. 1964) (writing that an OCI may exist when a government contractor "finds itself motivated by two competing interests ....”) The same author writes about "a clash, or the appearance of a clash," of interests at issue in individual conflicts of interest. Pasley, supra note 16.

${ }^{18}$ FAR $\S 2.101$.
} 
organization--referred to as "a person" in the FAR definition. Since this is a definition of an OCI, not a personal conflict of interest, we have to presume that the FAR is using the word "person" in the legal sense, which would include treating a company or other organization as a "person."19 The conflicted party's interest in the situation is somewhat camouflaged behind the words "because of other activities or relationships with other persons." The intent, apparently, is to refer to the organization's financial interests that are at stake in carrying out the organization's responsibilities to a third party--"to render impartial assistance or advice to the Government” and to provide "objectivity in performing the contract work." Both of the quoted phrases entail the risk of biased judgment typical in conflicts of interest. ${ }^{20}$ Where, for example, a contractor's employee is asked to provide advice to the government, and the employee's company stands to gain or lose additional contracts, depending on what advice the employee provides to the government, there is an OCI calling into question the employee's ability to render impartial advice.

What of the final phrase of the definition--“a person has an unfair competitive advantage”? It is something of a challenge to fit it into the conflict framework. While one could say that every company has an obligation to compete without unfair advantages, calling this an OCI seems like a semantic stretch. Having an unfair competitive advantage, notably, is not related to the biased judgment that is otherwise the hallmark of a conflict of interest. Even in the situation where an unequal access to information case sounds most like an OCI - where a firm has access to nonpublic information due to its work under a prior contract and that information may help the firm in competing for a future contract - the situation would be just as troubling if the firm had never held a prior government contract, but had instead gained access to the nonpublic information by, for example, receiving it through an inadvertent disclosure by the government, or by hacking into the government's computer files or bribing a government official - or, for that matter, through industrial espionage. The problem in those cases is that the competition is tainted, not that the taint arose due to a firm's prior contract. This is not to say that unfair competitive advantages are good--but it may be confusing and inappropriate to say that they create an organizational (or any other kind of) conflict of interest. ${ }^{21}$

Be that as it may, based largely on the language in FAR subpart 9.5, the caselaw has divided OCIs into three groups, referred to as biased ground rules, unequal access to

\footnotetext{
19 See 15 No. 1 NASH \& CIBINIC REP. 1 (Jan. 2001) (finding the use of the word “person” misleading and, more generally, questioning the adequacy of the regulatory guidance).

${ }^{20}$ Indeed, there may be no meaningful difference between the two phrases, other than that the first appears to relate to situations where a firm has a contract to provide assistance or advice, while the second may refer to contract work that does not, on its face, look like the provision of assistance or advice.

${ }^{21}$ For example, FAR 9.505-2 recognizes that certain competitive advantages are inevitable, such as those enjoyed by development contractors. A contractor who designs and developers certain items will often be in the best position to provide that item because "[d]evelopment contractors can frequently start production early and more knowledgeably than firms that did not participate in the development, and this can affect the time and quality of production, both of which are important to the government.” FAR 9.505-2(a)(3). The FAR therefore acknowledges this advantage, but concludes that "while the development contractor has a competitive advantage, it is an unavoidable one that is not considered unfair; hence no [OCI] prohibitions should be imposed.” Id.
} 
information, and impaired objectivity, and have treated each of those three groups somewhat differently. "Biased ground rules" refers to situations where a company sets the ground rules for a future competition by, for example, writing the specifications that competitors for a contract must meet. "Unequal access to information" arises where a company has access to nonpublic information (typically through performance of a contract) that gives it an unfair advantage in the competition for a later contract. "Impaired objectivity" comes into play when a company is asked to perform tasks that require objectivity, but another role the company plays casts doubt on the company's ability to be truly objective (for example, where a company is to give the government an assessment of the performance of firms, where one of those firms is an affiliate of the company giving the assessment). ${ }^{23}$

\section{Litigating OCIs in the Context of Federal Procurements}

When litigation has arisen regarding OCIs in the context of federal procurement, the FAR language is the governing law. The context of that litigation is bid protests--challenges brought by bidders dissatisfied with a contracting agency's conduct of a procurement. Bid protests can be filed with the contracting agency, GAO, or the U.S. Court of Federal Claims (COFC). ${ }^{24}$

The vast majority of bid protests are filed by a private firm concerned that a federal agency has treated it improperly and thus given another private firm an unfair advantage in the competition for a federal contract. A far smaller number of bid protests involve competitions between private firms and public-sector employees, although a number of significant conflict of interest decisions have arisen from those competitions. The public/private competitions are conducted pursuant to a directive of the Office of Management and Budget referred to as OMB Circular A-76, and the competitions are sometimes referred to as "A-76 competitions." In these competitions, federal employees propose a "most efficient organization” (MEO), typically a slimmed-down version of the

\footnotetext{
${ }^{22}$ The earliest GAO bid protest decision to use this terminology was Aetna Government Health Plans, Inc.; Foundation Health Federal Services, Inc., B-254397 et al., July 27, 1995, 95-2 CPD ๆ 129. The COFC cited the Aetna decision and its categorization of OCIs. See, e.g., Vantage Assocs., Inc. v. United States, 59 Fed. Cl. 1, 10 (2003).

${ }^{23}$ Although the published decisions, following the FAR, tend to treat them separately, the "biased ground rules" cases would appear to be simply a subset of the "impaired objectivity" cases: in all these situations, the conflicted entity is the contractor; its interest is in obtaining more money from the government (typically, but not always, through the award of future contracts); and its responsibility to a third party is the contractor's obligation to provided unbiased advice to the government. The "biased ground rules" cases are those where the contractor is providing advice about the ground rules (typically by drafting specifications) for a competition for a future contract. Obviously, if the contractor has an interest in winning that competition, it has a conflict of interest that calls into doubt its ability to provided unbiased advice about the appropriate specifications--in other words, it risks having impaired objectivity. ${ }^{24}$ GAO decides protests under the authority of the Competition in Contracting Act of 1984. 31 U.S.C. $\S \S 3551-56$ (2000). The COFC’s post-award bid protest jurisdiction is codified at 28 U.S.C. § 1491(b)(4). With a few exceptions, bid protests may be brought by bidders to challenge the procurement actions of any U.S. federal agency. Other than the COFC's bid protest decisions, there are only a limited number of court decisions addressing OCIs. See, e.g., United States ex rel. Harrison v. Westinghouse Savannah River Co., 352 F.3d 908 ( $4^{\text {th }}$ Cir. 2003); LeBoeuf, Lamb, Greene \& MacRae, L.L.P. v. Abraham, 347 F.3d 315 (D.C. Cir. 2003).
} 
workforce currently performing the work, and that MEO is compared to the best offer received from the private sector to see whether the work should be retained in-house or contracted out.

Whether in the setting of public/private competitions or the more typical private/private competitions for federal contracts, OCI allegations in bid protests take one of two forms: a protester may allege either that an OCI has tainted the procurement process or that a competitor should be excluded from the competition (in part or entirely) because that firm's performance of the contract would create an OCI. ${ }^{25}$ In either of these contexts there is a dispute about whether an OCI exists (or may arise)--essentially, these cases turn on whether the elements of an OCI are present (or, again, may arise). Separate from these cases where the parties dispute the existence of an OCI are the protests where the contracting agency recognized an actual or potential OCI, but the protester contends that the agency's steps to address it were legally inadequate, or, in the case of a party excluded from competition, that the agency improperly determined that the protester has an OCI that cannot be mitigated. We address each of those situations in turn. ${ }^{26}$

\section{OCIs Tainting the Procurement Process}

Where an award that has been made is alleged to have been tainted by an OCI, resolution of a protest will usually turn on the alleged "taint." A straightforward example is presented by CDR Enterprises, Inc., where the protester alleged that the firm that won the competition should have been rejected due to an OCI, created both by its alleged role in drafting the solicitation's statement of work and by its "direct oversight relationship" during the process of selecting the winner of the competition. ${ }^{27}$ After developing the protest record, GAO concluded that the allegedly conflicted firm had not played a significant role in either the drafting of the statement of work or the selecting of the winner of the competition. The result was that there was no conflict, and the protest was therefore denied. ${ }^{28}$

\footnotetext{
${ }^{25}$ FAR 9.502(c) may be capturing this distinction when it states: “An organizational conflict of interest may result when factors create an actual or potential conflict of interest on an instant contract, or when the nature of the work to be performed on the instant contract creates an actual or potential conflict of interest on a future acquisition."

${ }^{26}$ We note that GAO generally conducts hearings in only a small minority of protests. With regard to protests that involve OCIs, however, GAO appears to conduct a proportionately higher number of hearings for those protests that result in a written decision. See, e.g., Science Applications Int'l Corp., B-293601.5, Sept. 21, 2004, 2004 CPD ๆ 201; PURVIS Sys., Inc., B-293807.3, B-293807.4, Aug. 16, 2004, 2004 CPD I 177; Science Applications Int'l Corp., B-293601, et al., May 3, 2004, 2004 CPD ๆ 96; Mechanical Equip. Co., Inc.; Highland Eng'g, Inc.; Etnyre Int’l, Ltd.; Kara Aerospace, Inc., B-292789.2, et al., Dec. 15, 2003, 2004 CPD ๆ 192; LEADS Corp., B-292465, Sept. 26, 2003, 2003 CPD ๆ 197.

${ }^{27}$ B-293557, Mar. 26, 2004, 2004 CPD ๆ 46.

${ }^{28}$ Similarly, in American Artisan Productions, Inc., B-292559, B-292559.2, Oct. 7, 2003, 2003 CPD ๆ 176, GAO held that the Department of the Interior reasonably concluded that the awardee's use of a particular subcontractor did not taint the procurement, because the subcontractor's involvement in developing the solicitation's specifications had been limited. In Snell Enterprises, Inc., B-290113, B-290113.2, June 10, 2002, 2002 CPD I 115, too, GAO denied the protest after finding that the protester had not provided evidence that the awardee had assisted in the preparation of the solicitation of the protested contract, and the agency denied that the awardee had had such a role. Similar reasoning led to protests being denied in
} 
A tainted procurement process has been alleged where someone playing a role in selecting the winner of the competition is said to have had an institutional stake in the outcome. The classic example in terms of GAO's bid protest caselaw is probably the Aetna case, cited above, where the OCI resulted from the work of a consultant who was helping the agency evaluate proposals, including the proposal of the company ultimately the winner of the competition - with whom the consultant's employer's affiliate was teamed as a subcontractor. The OCI tainted the source selection process, and the OCI was "complete," as it were, once the award was made.

The Aetna case is a good example of how sweeping the definition of the conflicted party can be in an OCI: the connection between a consultant's employer's affiliate's prime contractor may seem quite tenuous (and certainly could not have supported a claim of a personal conflict of interest), but that conflict nevertheless led GAO to sustain the protest. GAO's review of potential OCIs in these cases may turn on, first, whether the participation that allegedly tainted the source selection involved the exercise of discretion. This goes to the third element, the conflicted party's responsibility to a third party, with the government being the third party. If the contractor's responsibility to the government in Aetna had simply been photocopying, it is hard to see how that responsibility conflicts with the consultant's loyalty to his organization, so that presumably no OCI could arise. ${ }^{29}$ Because any OCI has already arisen, these cases, when they are litigated, may turn on whether any harm was actually done by the OCI. ${ }^{30}$

A number of protest decisions have been published addressing conflicts of interest that allegedly tainted the procurements in A-76 public/private competitions. The alleged conflicts have arisen where some of the federal employees evaluating the private-sector proposals would appear to have had an interest in finding the private-sector proposal unacceptable--to take the most extreme case, where the federal employees' own jobs are at risk in the competition. In DZS/Baker; Morrison Knudsen Corp., GAO found that 14 of the 16 federal employees who were assisting with the evaluation of private-sector proposals held positions at risk of being contracted out and therefore had an unacceptable conflict of interest. ${ }^{31}$ The conflict arises due to the tension between the employees' desire to further the MEO's interest (by winning the competition) and their duty to write unbiased ground rules (if MEO members are involved in writing the "performance work

M\&W Construction Corp., B-288649.2, Dec. 17, 2001, 2002 CPD ๆ 30, and in TRW, Inc., B-282162, B-282162.2, June 9, 1999, 99-2 CPD ๆ 12.

${ }^{29}$ Sometimes the second element in our OCI analysis is involved--whether the conflicted party has a stake in the situation. For example, in Teledyne-Commodore, LLC, B-278405.6, B-278408.5, Mar. 8, 1999, 99-1 CPD I 60, where GAO concluded there was no OCI because (among other reasons) the firm helping the agency evaluators during the procurement did not stand to gain any financial benefit from its recommendations.

${ }^{30}$ The record sometimes allows GAO to conclude that, while there was an OCI, it simply did not matter (in GAO's terms, the protester was not prejudiced). See, e.g., IT Facility Servs.-Joint Venture, B-285841, Oct. 17, 2000, 2000 CPD I 177 at 1, 4. The COFC similarly found that an OCI, if one existed, caused no prejudice in JWK Int'l Corp. v. United States, 52 Fed. Cl. 650, 655-59 (2002).

${ }^{31}$ B-281224 et al., Jan. 12, 1999, 99-1 CPD ๆ 19. 
statement” governing the competition) and to judge private-sector proposals fairly (if MEO members serve as evaluators). ${ }^{32}$

The A-76 cases highlight the contrast between the narrow definition of the conflicted entity in personal conflicts of interest, as opposed to the expansive definition in OCIs. In a competition involving only private firms, as demonstrated by the Aetna decision discussed above, GAO has taken an expansive approach in defining the organization and the "taint" that can lead to an OCI. By contrast, in the context of A-76 public/private competitions, where a conflict of interests is alleged involving individuals working for the government, GAO has carefully differentiated between, on the one hand, situations where the individual actually has a personal stake in the outcome of the competition (for example, by holding a position at risk) or his or her spouse has a stake in the outcome (where GAO has found a conflict of interest), and situations, on the other hand, where the person with the real stake in the outcome is merely a colleague, subordinate, or the like (where GAO has found that no conflict existed). ${ }^{33}$ In taking this strict approach, GAO could be said to treat the conflicts in the A-76 context more as personal conflicts, rather than organizational ones. ${ }^{34}$

There is one additional and somewhat unusual context in which protesters have alleged OCIs in A-76 competitions. Agencies, challenged by the perceived complexities of the A-76 process, are hiring consulting firms to help them--to help the federal employees put together their MEO staffing proposal, to help the agency put together the performance work statement defining the scope of the services being competed, and to help the agency evaluate the MEO plan and the private-sector proposals. As with in-house employees, there is clearly a risk of an OCI when the same consultant helps the MEO and performs

\footnotetext{
32 See also Jones/Hill Joint Venture, B-286194.4 et al., Dec. 5, 2001, 2001 CPD I 194 (finding that same agency personnel participated in drafting both the performance work statement and the MEO's management plan).

${ }^{33}$ A good example of the difference between the way colleagues and spouses are treated is the decision in IT Facility Services. On the one hand, GAO found in IT Facility Services that no conflict of interest was created merely because some evaluators had colleagues or subordinates whose job were at risk in the public/private competition at issue. Similarly, in Federal Management Systems, Inc. v. United States, 61 Fed. Cl. 364, 368-71 (2004), the COFC found that the fact that evaluators interact with individuals who hold positions in the function being competed, or direct some of their activities, does not create a conflict; and in JWK International Corp. v. United States, 52 Fed. Cl. 650, 655-59 (2002), the COFC rejected the argument that individuals working in units that merely interrelate with, or rely on, those under study have a conflict of interest. On the other hand, in IT Facility Services, GAO found that at least the potential of a conflict was created where the job of the spouse of one of the evaluators was at risk (but GAO concluded that the record demonstrated that that employee's conflict had not tainted the selection decision because, even if that evaluator's scores were ignored, the outcome would be the same). In fact, it would seem that a person's ability to be objective could be tainted by friendship or a collegial relationship. For example, where John needs to decide whether to send Mary or Bill to a week-long conference in Hawaii in January, and John is a good friend of Mary but not of Bill, John may be unfair to Bill in the selection. Nonetheless, people tend not to view that as a conflict of interest--not all bias is the result of a conflict of interest.

${ }^{34}$ It should be noted that GAO has recognized that FAR subpart 9.5 is not directly applicable to A-76 competitions, so that it could be argued that GAO does not see those competitions as raising organizational, rather than personal, conflict issues; instead, GAO referred to the FAR provisions as "address[ing] analogous situations" and "instructive in that it establishes whether similar situations involving contracting organizations would require avoidance, neutralization or mitigation.” DZS/Baker, 99-1 CPD I 19 at 2, citing Battelle Mem’l Inst., B-278673, Feb. 27, 1998, 98-1 CPD ๆ 107.
} 
the "above the fray" tasks of writing the performance work statement and evaluating proposals. $^{35}$

\section{OCIs Associated with Future Performance}

In contrast with the first type of OCI, where the competition for a contract has allegedly been tainted by a conflict, in the second type, the competition process here is untainted by an OCI, but performance of the contract will (allegedly) create a future OCI if a particular firm is awarded the contract. For example, in Johnson Controls World Services, Inc., GAO found an OCI where a firm would be required to perform installation support services, on the one hand, and then evaluate the efficiency of those services, on the other. ${ }^{36}$ Similarly, in Ktech Corp., GAO found an OCI where a subcontractor would have responsibility for testing Defense Threat Reduction Agency reentry bodies as well as for monitoring the performance of those tests. ${ }^{37}$

These cases sometimes turn on the first element of a conflict of interest, the identity of the conflicted party, notwithstanding the generally inclusive definition of conflicted parties in OCIs. Specifically, the cases may turn on whether two entities are really part of the same organization at all. For example, in American Management Systems, Inc., GAO found that two firms, while they did have a marketing alliance, were not related in terms of finances or performance obligations in such a way that gave rise to an OCI (even if particular actions of one helped the other, that would not entail the self-interest that is needed for there to be a conflict of interest). ${ }^{38}$

Where only one organization is involved, the cases may turn on the third element, the nature of the conflicted entity's responsibility to a third party. Where the responsibility involves the exercise of judgment or discretion, GAO may well find that there is an OCI. Where the responsibility is more ministerial or clerical, the relationship may not be found to be an OCI. ${ }^{39}$

\section{Failure to Address an OCI Adequately}

FAR 9.504(a) requires agencies” contracting officers to “(1) [i]dentify and evaluate potential organizational conflicts of interest as early in the acquisition process as possible; and (2) avoid, neutralize, or mitigate significant potential conflicts before contract award.” While recognizing that contracting officers need to examine each situation to address any OCI that is identified, the FAR provides some guidance,

\footnotetext{
35 See, e.g., Jones/Hill Joint Venture, 2001 CPD \ 194.

${ }^{36}$ B-286714.2, Feb. 13, 2001, 2001 CPD \ 20. Presumably, a firm’s evaluating the performance of one of its competitors' systems would be just as problematic as the firm's evaluating the performance of its own system, although that scenario is rarely addressed in the case law. For a brief mention of it, see PURVIS Systems, Inc. B-293807.3; B-293807.4, Aug. 16, 2004, 2004 CPD I 177 at 11.

${ }^{37}$ B-285330, B-285330.2, Aug. 17, 2000, 2002 CPD ๆ 77.

${ }^{38}$ B-285645, Sept. 8, 2000, 2000 CPD ๆ 163.

${ }^{39}$ See, e.g., Computers Universal, Inc., B-292794, Nov. 18, 2003, 2003 CPD ๆ 201 (concluding that monitoring, such as quality assurance, standing alone, does not create potential for impaired objectivity and thus OCI).
} 
including "general rules" that distinguish between "[p]reventing the existence of conflicting roles that might bias a contractor' judgment (what might be called pure OCI situations) and "[p]reventing unfair competitive advantage" arising because a contractor has access to proprietary or source-selection information. ${ }^{40}$ The FAR includes examples of certain conflicts that cannot be mitigated--for example, where a firm receives a contract to prepare a detailed plan for scientific and technical training of an agency's personnel, and then suggests a curriculum that the agency endorses and incorporates in its request for proposals to institutions to establish and conduct the training, the firm may not be awarded a contract to conduct the training. ${ }^{41}$ The FAR also provides, however, that the head of an agency (or a designee) may "waive any general rule or procedure of this subpart by determining that its application in a particular situation would not be in the Government's interest." ${ }^{, 2}$ The FAR sets out certain situations where an apparent OCI situation is defined as not constituting an improper OCI, and where an agency has reasonably found that one of those exceptions applies, a protest alleging an improper OCI was denied. ${ }^{43}$

Where protests have been sustained on OCI grounds, it is usually because the agency failed to identify an OCI, or, having recognized a potential OCI, failed to deal with it in a legally adequate way. Thus, where the agency denies that an OCI exists, GAO and the COFC appear to show little deference, if the reviewing forum concludes that an OCI should have been identified. For example, in PURVIS Systems, Inc., the Navy (and the allegedly conflicted party, Northrop Grumman Defense Mission Systems, Inc.) argued that the contract services were purely "objective data measurements," but GAO found that the services would require "subjective contractor input and judgment," so that the agency had to address the possibility of a potential "impaired objectivity" OCI. ${ }^{44}$ In Ktech Corporation, GAO sustained the protest after concluding that the agency had failed to consider OCIs (both "unequal access to information" and "impaired objectivity"), where GAO found evidence supporting both kinds of OCI. ${ }^{45}$ In one case, the COFC ruled in favor of a protester alleging that a competitor should have been excluded due to an OCI, because the court held that the contracting officer had failed to identify the OCI "as early in the acquisition process as possible," as required by FAR 9.504(a). The court also rejected the contracting officer's conclusion that no OCI existed; in the facts

\footnotetext{
${ }^{40}$ FAR 9.505

${ }^{41}$ FAR 9.508 (g).

${ }^{42}$ FAR 9.503. GAO appears to review the reasonableness of an agency's explanation supporting a waiver. See Knights’ Piping, Inc.; World Wide Marine \& Indus. Servs., B-280398.2, B-280398.3, Oct. 9, 1998, 98-2 CPD ๆ 91 at 5.

${ }^{43}$ See, e.g., Vantage Assocs., Inc., 59 Fed. Cl. at 10-13 (2003) (holding that both the "developmental contractor" and the "industry representative" exceptions apply, see FAR 9.505-1 and 9.505-2(a)(1)(ii), and noting, at 12, the "deferential standard of review" on the OCI issue).

${ }^{44}$ PURVIS Sys., Inc., 2004 CPD 9 177. In Mechanical Equipment Co., Inc. et al., B-292789.2 et al., Dec. 15, 2003, 2004 CPD ๆ 192, GAO found reasonable the Army’s conclusion that no significant OCI existed. GAO also found reasonable the Air Force's determination that no OCI existed in Wyle Labs., Inc., B-288892, B-288892.2, Dec. 19, 2001, 2002 CPD \ 12.

${ }^{45}$ Ktech Corp., 2000 CPD I 12. A somewhat unusual case is J\&E Associates., Inc., B-278771, Mar. 12, 1998, 98-1 CPD I 77, where GAO sustained a protest challenging the terms of a solicitation, because GAO concluded that the solicitation was required to include a provision addressing potential OCIs.
} 
presented, the court found an actual OCI because the firm at issue occupied an "impermissible dual role." 46

Neither the FAR nor the caselaw provides much specific guidance regarding appropriate steps for mitigating an OCI that has been identified. While obviously any mitigation plan needs to be tailored to the nature of the specific OCI, some points can be suggested. For example, where in an "unequal access to information" OCI, sharing more information with competing offerors may adequately mitigate the OCI. ${ }^{47}$ It would also seem feasible to put a "firewall" around the individuals with access to the "extra" information to ensure that they do not share the information with individuals who could use it to gain an unfair competitive advantage. Where an "impaired objectivity" OCI is at issue, it is difficult to see how a firewall within the conflicted organization would mitigate the OCI, in light of the assumption in these OCIs that all employees of the organization will work to further the organization's interest. Placing a firewall between the organization and other organizations may make sense, although it is not entirely clear what such a firewall would entail. While the FAR does not provide guidance at this level of specificity, there have been a number of decisions finding reasonable an agency's reliance on a mitigation plan under which a subcontractor would handle situations where the prime contractor would be conflicted (or vice versa). ${ }^{48}$

More generally, where an agency has recognized the potential OCI and taken steps to address it (in the FAR's language, steps to “avoid, neutralize, or mitigate” it), both GAO and the COFC appear inclined to deny any protest, absent some clear reason to find the agency's action inadequate. ${ }^{49}$ The best example of the distinction between what causes an OCI protest to be sustained and what leads to its being denied may be the pair of protests filed by Science Applications International Corporation (SAIC) at GAO. In SAIC's first protest, the firm challenged the conclusion of the contracting agency (the Environmental Protection Agency) that no OCI could arise during performance by Lockheed Martin Services, Inc. and that the agency therefore did not need to consider the impact of an OCI in selecting the Lockheed Martin for award; GAO found, after conducting a hearing, that the record demonstrated (and agency personnel conceded) that the factual premise for an "impaired objectivity" OCI could arise. Because the agency

\footnotetext{
${ }^{46}$ Filtration Dev.Co., LLC v. United States, 60 Fed, Cl. 371, 379 (2004). The court also found that the protester was entitled to a presumption that it was prejudiced by the OCI. Id. at 379-80.

${ }^{47}$ See Sierra Military Health Servs., Inc. v. United States, 58 Fed. Cl. 573, 583 (2003).

${ }^{48}$ See, e.g., Deutsche Bank, B-289111, Dec. 12, 2001, 2001 CPD ๆ 210; Epoch Eng’g, Inc., B-276634, July 7, 1997, 97-2 CPD ๆ 72; SC\&A, Inc., B-270160, B-270160.2, Apr. 10, 1996, 96-1 CPD ๆ 197.

${ }^{49}$ Thus, in LEADS Corp., GAO found that the Army had reasonably addressed the potential for OCIs during performance. In Johnson Controls World Services, Inc., B-286714.3, Aug. 20, 2001, 2001 CPD I 145, GAO denied a protest challenging the Army's corrective action taken to address the OCIs identified in a prior protest sustained by GAO. See Johnson Controls World Services, Inc.,B-286714.2, Feb. 13, 2001, 2001 CPD ๆ 20. In Knights’ Piping, Inc.; World Wide Marine \& Industrial Services., B-280398.2, B-280398.3, Oct. 9, 1998, 98-2 CPD ๆ 91, GAO found that the Navy had reasonably determined that adequate safeguards were in place to address an OCI; in addition, the agency had properly executed a waiver of OCI restrictions, as permitted under FAR 9.503. In Sierra Military Health Services, 58 Fed. Cl. 573, 583 (2003), the COFC denied a motion for a preliminary injunction, in part, because (so it appears from a somewhat cryptic discussion) it found that the agency could later adequately address an "unequal access to information" OCI by disclosure of information to other competitors.
} 
had not considered the impact of this prior to award, GAO sustained this first protest. ${ }^{50}$ After the agency then reviewed additional information and set up procedures to address any conflict that might arise during performance, SAIC protested again, alleging that the agency's action was legally inadequate (largely because the agency continued to argue that no OCI would arise). GAO found that the agency had adequately addressed the potential OCI, and the protest was therefore denied. ${ }^{51}$

Where a contracting officer sees a potential OCI and excludes the firm at issue from a competition, and that firm then protests its exclusion, both GAO and the COFC seem reluctant to sustain the protest. $^{52}$ In what would appear to be an unusual situation, however, in one case the contracting officer recognized a potential OCI if the protesting firm were to win the contract at issue and concluded that, notwithstanding the firm's proposed mitigation plan, the firm's proposal should be excluded from further consideration for award. ${ }^{53}$ The firm then protested to the COFC, which found that the contracting officer had failed to meaningfully consider the firm's mitigation plan and acted unreasonably in concluding that the firm had "an unavoidable or unmitigable OCI." 54

\section{Apparent vs. Actual OCIs}

The word "apparent" can cause mischief, or at least confusion, in the context of OCIs. One hears reference to an "apparent OCI," which sounds like a contrast to an "actual OCI.” It may be more appropriate, however, to say that OCIs are always a matter of appearance. For example, in the Aetna and DZS/Baker cases, the question was not whether the consultant or evaluators provided biased assessments of the proposals they were evaluating--the question was whether a reasonable person would find that their objectivity could have been impaired by a conflict of interest, regardless of the individuals' integrity. In other words, the issue is not the reality of the individuals' conduct and its fairness, but the reality of the conflict that the individual faced.

In any event, the "appearance" issue plays out differently in different contexts. Where an award that has been made is alleged to have been tainted by an OCI, the OCI has already arisen. Where the award process is untainted, but the firm awarded the contract will face an OCI in performance, the OCI is prospective. In the former group, there is sometimes a possibility of demonstrating that the award was untainted, as in the IT Facility Services

\footnotetext{
50 Science Applications Int'l Corp., 2004 CPD ף 96.

51 Science Applications Int'l Corp., 2004 CPD ๆ 201.

${ }^{52}$ For example, in SSR Engineers, Inc., B-282244, June 18, 1999, 99-2 CPD ๆ 27, GAO concluded that the Navy had reasonably excluded the protesting firm from competing in a procurement due to an OCI caused by its role in preparing the statement of work and cost estimate; in Basile, Baumann, Prost \& Associates, Inc., B-274870, Jan. 10, 1997, 97-1 CPD \ 15, GAO found that the Army had reasonably excluded a firm from competing under a solicitation because the firm had prepared the statement of work and cost estimate used by the agency; and in DSD Labs., Inc. v. United States, 46 Fed. Cl. 467 (2000), the COFC found that the contracting officer had acted reasonably in finding that an OCI precluded the protester from competing. 53 Informatics Corp. v. United States, 40 Fed. Cl. 508 (1998).

${ }^{54} \mathrm{Id}$. at 518.
} 
case mentioned early. Obviously, where the conflict is prospective, there is no way to prove that it will cause no harm.

Instead, for the prospective OCI cases (and occasionally in allegedly tainted award cases, too), the case turns on the nature of the services to be provided in the future. That question goes to what we have described as the third element of conflicts of interest. Specifically, the question becomes whether the contractor will be asked to perform work where judgment is needed. Obviously, if no judgment is needed, there is no risk of biased judgment. ${ }^{55}$ Where the nature of the services to be provided is such that potential bias could have an impact, an apparent conflict of interest may well need to be addressed.

\section{Conclusion}

OCIs are a significant part of the landscape of public procurement today. They present challenges to the integrity of the procurement system, and they can create difficult situations for contracting agencies, for firms that are potentially conflicted, and for their competitors. The factors leading to OCIs are unlikely to disappear: the consolidation within the industrial sectors selling to the government, mergers and acquisitions leading to the presence of multifaceted corporations selling a wide range of goods and services to the government, the reliance on umbrella contracts, and public/private competitions. At least in the federal procurement system, OCIs look like a "growth area" for public procurement practitioners, and one that bears watching.

\footnotetext{
${ }^{55}$ For example, in Computers Universal, Inc., 2003 CPD \ 201, GAO found that the work to be performed under the contested contract did not involve subjective evaluative judgment, no "impaired objectivity” OCI could arise. Similarly, in TDS, Inc., B-292674, Nov. 12, 2003, 2003 CPD I 204, GAO found that the awardee would not have an "impaired objectivity” OCI notwithstanding the firm's proposed subcontractor's other work for the agency, where the subcontractor would not be put in a position to evaluate the prime contractor's performance.
} 